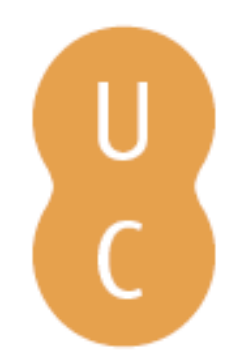

\title{
nommalina
}

\section{El exilio político portugués en Estados Unidos: prensa y propaganda (19301945)}

\author{
Autor(es): PenaRodríguez, Alberto
}

Publicado por: Imprensa da Universidade de Coimbra

URL

persistente: URI:http://hdl.handle.net/10316.2/39012

DOI: $\quad$ DOI:http://dx.doi.org/10.14195/978-989-26-1064-1_18

Accessed : $\quad$ 26-Apr-2023 08:41:00

A navegação consulta e descarregamento dos títulos inseridos nas Bibliotecas Digitais UC Digitalis, UC Pombalina e UC Impactum, pressupõem a aceitação plena e sem reservas dos Termos e Condições de Uso destas Bibliotecas Digitais, disponíveis em https://digitalis.uc.pt/pt-pt/termos.

Conforme exposto nos referidos Termos e Condições de Uso, o descarregamento de títulos de acesso restrito requer uma licença válida de autorização devendo o utilizador aceder ao(s) documento(s) a partir de um endereço de IP da instituição detentora da supramencionada licença.

Ao utilizador é apenas permitido o descarregamento para uso pessoal, pelo que o emprego do(s) título(s) descarregado(s) para outro fim, designadamente comercial, carece de autorização do respetivo autor ou editor da obra.

Na medida em que todas as obras da UC Digitalis se encontram protegidas pelo Código do Direito de Autor e Direitos Conexos e demais legislação aplicável, toda a cópia, parcial ou total, deste documento, nos casos em que é legalmente admitida, deverá conter ou fazer-se acompanhar por este aviso.

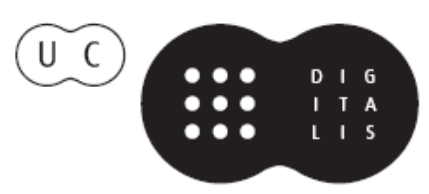


A L B ERTO PENA-RODR ÍGUEZ HELOISA PAULO

COOR D.

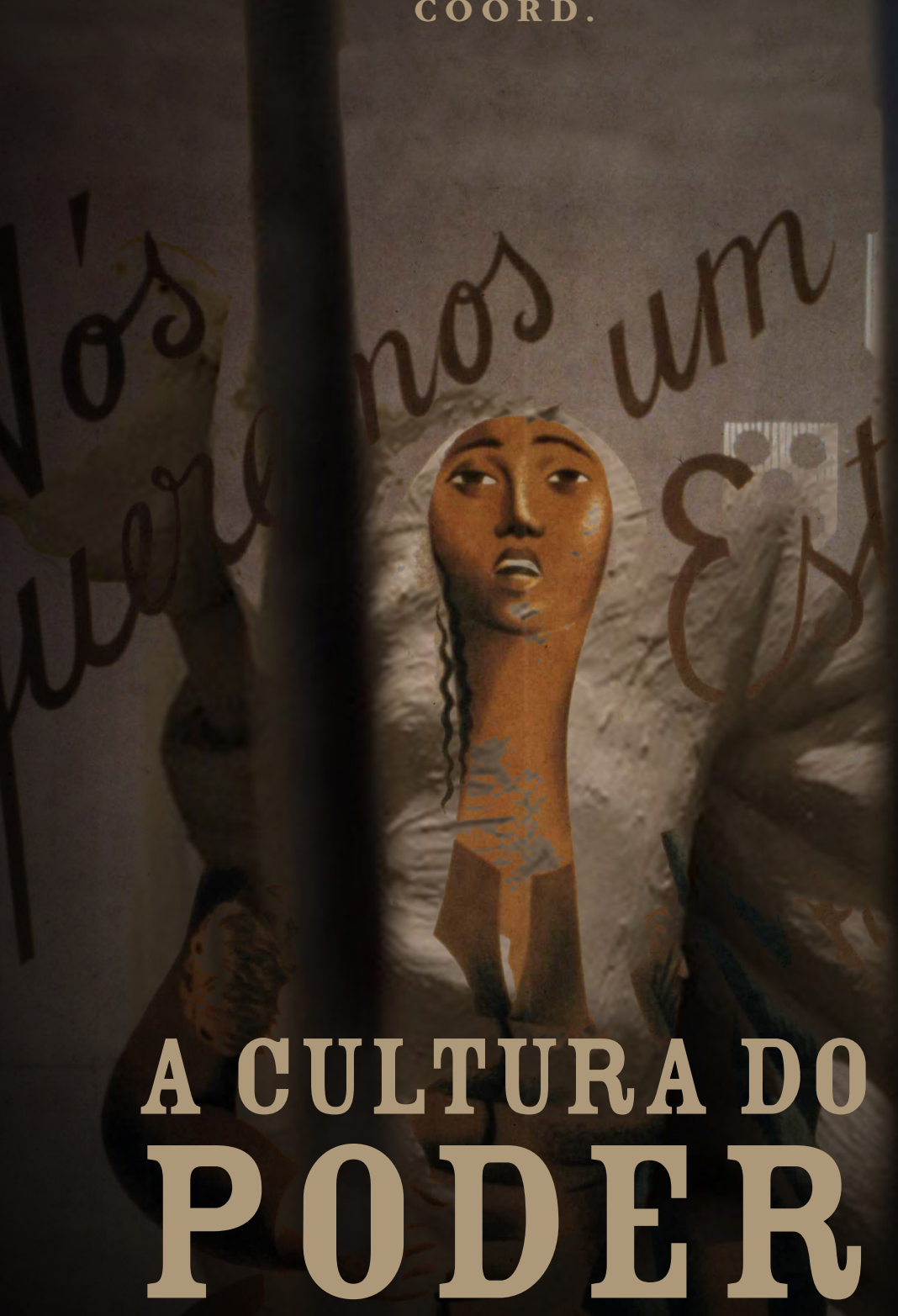

A PROPAGANDA INOS ESTADOS AUTORITÁRIOS 


\section{EL EXILIO POLÍTICO PORTUGUÉSEN ESTADOS UNIDOS: PRENSA Y PROPAGANDA（1930-1945)}

Alberto Pena-Rodríguez ${ }^{1}$

\section{Salazarismo, emigración y propaganda}

El Estado Novo ha sido el régimen político que ha tenido más impacto en la emigración portuguesa. Aunque la dictadura fue formalmente fundada en 1933 con la aprobación de la Constitución Política concebida por António de Oliviera Salazar, esta se inicia con el golpe de Estado del 28 de mayo de 1926 y se extiende hasta 1974. Cuarenta y ocho largos años que han afectado a la forma que muchos emigrantes portugueses veían y sentían su país. Años en los que, a las razones económicas se unieron los motivos políticos para abandonar Portugal. ${ }^{2}$ Miles de portugueses emigraron a diferentes

\footnotetext{
${ }^{1}$ Este trabajo forma parte de los resultados del proyecto de investigación titulado "Portugal, España y los Estados Unidos de América. La representación de las dictaduras ibéricas en el discurso periodístico luso-americano (1936-1945)”, patrocinado por la Harvard University y financiado a través de una Beca de Movilidad Sénior del Ministerio de Educación de España (PRX12/00024), Universidade de Vigo.

2 Véase: SANTOS, Vanda (autora), Carneiro, Roberto (coord.) (Observatório da Emigração). O discurso oficial do Estado Novo nos anos 60 a 80 e imigração dos anos 90 à atualidade. Lisboa: Alto Comisionado para Imigração e Memórias Étnicas, 2004 .
} 
países europeos, Brasil, Estados Unidos y Canadá. 3 En cifras absolutas, no fue el período en el que más portugueses llegaron a Estados Unidos, principalmente por las restricciones fronterizas en los años treinta (sólo entraron 3.518) y cuarenta (6.765). ${ }^{4}$ Aunque la llegada de inmigrantes lusos fue creciendo (13.928 en la década de 1950), la mayoría de los que abandonaron Portugal en este período lo hicieron en el tramo final de la dictadura, durante la década de 1960 (70.568) y 1970 (104.754).5 Muchos eran azorianos que huían de las erupciones del volcán de Os Capelinhos y portugueses con motivaciones esencialmente económicas. ${ }^{6}$ Algunos de ellos, probablemente, huían también de su alistamiento para combatir África, en las guerras coloniales. En el conjunto de inmigrantes portugueses, no se conoce la existencia de un registro discriminado del número de exiliados políticos que se establecieron en Estados Unidos. Se sabe, en cualquier caso, que el territorio norteamericano no fue el lugar predilecto para los que huían de Portugal por motivos puramente políticos. Algunos de los que emigraron por razones económicas asumirían la condición de exiliados políticos cuando comenzaron a colaborar con acciones de oposición a la dictaura en el exterior o por su identificación con la propaganda anti-salazarista. La mayoría prefirieron establecerse en España (en los años previos a la Guerra Civil, entre 1926 y 1936), Francia y Brasil. Aunque hubo

\footnotetext{
3 Para un conocimiento completo de este fenómeno consúltese el Observatório da Emigração (ISCTE, Lisboa), que dispone de una información detallada por países. En el caso de Estados Unidos de América, véase: http://www.observatorioemigracao. secomunidades.pt/np4/paises.html?id=230

${ }^{4}$ Según los datos del Handbook of Inmigration Statistics 2012.

5 Ibídem.

${ }^{6}$ Léase a BAGANHA, Maria. Portuguese Emigration to the United States. New York: Garland Publishing, Inc., 1990. Ténganse en cuenta también las siguientes referencias: PENA, Alberto, MESQUITA, Mário y VICENTE, Paula (coords.). Galiza e Açores-A Rota Americana. Lisboa: Almedina, Fundação Luso-Americana e Consello da Cultura Galega, 2012. Y ROCHA, Gilberta Pavão Nunes: "Azorean Emigration in the context of social change: some note from the press in São Miguel (1920-1950)". In E-Journal of Portuguese History, vol. 7, $\mathrm{n}^{\circ}$ 2, winter 2009.
} 
grupos de exiliados en otros muchos países, europeos y americanos. A pesar de la aparente irrelevancia del exilio político portugués en Estados Unidos por la falta de estudios monográficos, lo cierto es que en territorio norteamericano se desarrolló una intensa actividad política y propagandística en contra y a favor de la dictadura en el entorno de la colonia, que derivó en presiones al gobierno de Estados Unidos y la organización de Naciones Unidas en determinados momentos históricos, por parte de uno y otro bando. El período de mayor intensidad propagandística en el que la prensa luso-americana jugó un papel muy importante, fueron los años que van desde el inicio de la Guerra Civil española hasta el final de la Segunda Guerra mundial (1936-1945). Tras este período, el debate político y las campañas de prensa remitieron en el seno de la colonia. Sin embargo, la creciente influencia diplomática de Estados Unidos, hizo que los opositores al Estado Novo redoblasen su acción política a través de instituciones como el Portuguese-American Commitee for Democracy, fundada en febrero de 1945 por el ex ministro João Camoesas, el ex cónsul de Portugal en Providence, Abílio de Oliveira Águas, y el escritor de ascendencia gallega José Rodrigues Miguéis. El también llamado Comité Luso-Americano Pró-Democracia desarrolló diversas acciones de carácter político y propagandístico, entre otras la difusión del memorándum, firmado por João Camoesas el 11 de junio de 1945, dirigido al presidente de la Conferencia de Organización Internacional de las Naciones Unidas. ${ }^{7}$

En este contexto, el estudio del comportamiento político de la inmigración portuguesa en Estados Unidos es un aspecto de la historia contemporánea de Portugal que reúne numerosos elementos de gran interés. En primer lugar, porque puede revelar las relaciones que la

7 "Memorandum dirigido ao Presidente da Conferência da Organização Internacional das Nações Unidas" (publicado también en versión inglesa). Diario de Noticias (New Bedford), 28 de julio de 1945, s. p. 
dictadura portuguesa mantuvo con una de las comunidades lusas más importantes en el exterior, que durante los años treinta rondaba el medio millón de personas repartidas entre las comunidades de Nueva Inglaterra y California. En segundo lugar, porque podría aportar datos sobre cuál ha sido el nivel de implicación política de los sucesivos gobiernos del Estado Novo con sus ciudadanos emigrados a Estados Unidos. Principalmente, porque el entorno político local y el sistema político democrático en el que se integraban los inmigrantes portugueses era incompatible con la creación de un régimen político que conculcaba derechos fundamentales reconocidos por la democracia americana, considerados sagrados para el ejercicio de la vida política, como el derecho de reunión, de libre asociación, de pensamiento político, de libertad de prensa y de expresión. ${ }^{8}$

Los portugueses que llegaron a Estados Unidos en los años treinta y cuarenta y los que ya allí estaban establecidos, hubieron de aprender a relacionarse con el ideario político salazarista y unas estructuras de poder que chocaban frontalmente con el modo de vida de la democracia americana. Muchos tuvieron dificultades para encontrar un encaje espiritual entre en amor a su patria y su identificación con el sistema de libertades americano. Especialmente, porque el Estado Novo se apropió de todos los elementos mitológicos y espirituales que formaban parte del ideario nacional portugués. El Estado Novo trató de convertirse en el catalizador de todos los

\footnotetext{
${ }^{8}$ El único trabajo sobre este tema es la tesis de mestrado inédita de Rui Antunes Correia, "Salazar en New Bedford. Leituras Luso-Americanas do Estado Novo". Lisboa: Universidade Aberta, 2004. (Tese orientada pela Prof. Maria Filipa Palma dos Reis). En ella se hace un abordaje serio y riguroso sobre esta cuestión a partir del estudio del Diario de Noticias de New Bedford en los años treinta. Este trabajo fue publicado en un formato resumido por el Center for Portuguese Studies and Culture de la University of Massachusetts Dartmouth. Véase: "Salazar in New Bedford: political readings of Diario de Noticias, the only Portuguese daily newspaper in the United States". In HOLTON, Kimberly DaCosta, e KLIMT, Andrea (edited by). Community, Culture and the Making of Identity: Portuguese-Americans along the Eastern Seaboard. North Dartmouth, Massachusetts: University of Massachusetts Dartmouth-Center for Portuguese Studies and Culture, 2009, pp. 227-244.
} 
signos identitarios, como un modelo político totalizador que asumía la representación máxima de la nación portuguesa, no sólo a nivel político y económico, sino, sobre todo, en una dimensión cultural. Era lo que la propaganda del régimen llamó la "revolução nacional", uno de cuyos pilares fundamentales era la renovación moral del país a través de la llamada "política do espírito", para cuya difusión y expansión se creó, como se sabe, el Secretariado de Propaganda Nacional (SPN) en septiembre de 1933 bajo la dirección del escritor modernista António Ferro.9 Su objetivo era el de "iluminar" al mundo sobre el "caso portugués", según la expresión del propio director. ${ }^{10}$ Era un arma esencial de la política salazarista, “(...) tanto mais que muitos portugueses sofrem o complexo de inferioridade de só acreditarem que fizeram alguma coisa quando os estrangeiros tho repetem, quando se sentem envaidecidos com os seus elogios (...)” (cursiva en el original), decía Ferro. ${ }^{11}$ El SPN jugó un papel primordial en la construcción retórica del Estado Novo. Como ya se ha publicado en otros estudios, su misión fundamental era proteger al gobierno de la dictadura de las campañas de propaganda contrarias a su política y difundir su propia visión de la realidad para captar adeptos para su causa, así como popularizar los principios ideológicos sobre los que asentaba el nuevo Estado portugués. El SPN trató de que la sociedad portuguesa ganase confianza en sí misma confiando en Salazar y su gobierno. ${ }^{12}$ Trató también de ganarse la voluntad de los emigrantes portugueses, para que sintiesen orgullo de la patriótica obra del Estado Novo, de lo "nacional", dentro de ese proceso de

\footnotetext{
9 RAMOS DE Ó, Jorge. Os Anos de Ferro. O dispositivo cultural durante a "Política do Espírito", 1933-1949. Lisboa: Estampa, 1999.

${ }^{10}$ FERRO, António. Dez Anos de Política do espírito (1933-1943). Discurso proferido no $X$ aniversário do SPN. Lisboa: Edições do SPN, 1943, p. 16.

11 Ibídem.

12 Véase: PENA RODRÍGUEZ, Alberto: Tudo pela Nação, Nada contra a Nação. Salazar, la creación de Secretariado de Propaganda Nacional y la censura". In Hispania. Revista Española de Historia, 2012, Vol. LXXII, n. ${ }^{\circ}$ 240, enero-abril, pp. 177-204.
} 
transformación espiritual, como se conoce a través de los estudios realizados por Heloisa Paulo sobre las campañas de propaganda salazarista entre la comunidad de inmigrantes portugueses de Brasil. ${ }^{13}$ Para alcanzar su objetivo nacionalizador (léase salazarista) la dictadura ejerció un control férreo sobre la opinión pública, partiendo de la divisa, inspiradora de la estrategia de propaganda del régimen, que decía: "Não pode haver liberdade contra a verdade, não pode haver liberdade contra o interesse comum". ${ }^{14}$

Inalterable políticamente, anclado en los designios de un liderazgo personalista que se inspiraba en principios políticos basados en un tradicionalismo conservador, cristiano y nacionalista, el Estado Novo estaba articulado en un sistema institucional corporativo que fue creado en un momento histórico en el que los modelos autoritarios se estaban imponiendo en Europa frente a las democracias parlamentarias. ${ }^{15}$ Era una época de un populismo exacerbado en el que el adoctrinamiento masivo de los nuevos idearios revolucionarios, basados en liderazgos mesiánicos, se sirvieron de la propaganda, que contaba con nuevas técnicas y medios de gran eficacia para persuadir a las masas. La retórica propagandística del fascismo y el nazismo fue especialmente movilizadora. ${ }^{16}$ Porque supo aprovechar todas las técnicas y los recursos de comunicación a su disposición para orquestar campañas permanentes que perseguían la creación de un movimiento político mayoritario, un consenso sin disenso alrededor de un proyecto de unidad nacional. La prensa y los entonces nuevos

13 PAULO, Heloisa. Estado Novo e Propaganda em Portugal e no Brasil. O SPN/ SNI e o DIP, Coimbra, Minerva, 1994. De la misma autora: Aqui também é Portugal. Coimbra: Quarteto, 2000.

14 MATOS, Helena. Salazar. A Construção do Mito (1928-1933). Lisboa: Temas e Debates-Círculo de Leitores, 2010.

15 Para comprender el Estado Novo, léase: TORGAL, Luis Reis. Estados Novos, Estado Novo. Coimbra: Imprensa da Universidade, $2^{a}$ edição, 2009.

16 Véase: TORGAL, Luis Reis, y PAULO, Heloisa. Autoritarismos, totalitarismos $e$ suas representações. Coimbra: Imprensa da Universidade, 2008. 
medios audiovisuales (la radio y el cine) fueron instrumentos de comunicación que acrecentaron la capacidad de persuasión de los partidos y los regímenes autoritarios.

Se produjo no sólo una transformación política, sino también un cambio social. Un cambio de mentalidad basado en la cultura del poder que otorgaba la propaganda como instrumento de control de las conciencias. Este cambio afectó a los sectores sociales identificados con este tipo de movimientos políticos, que incorporaron al discurso público los valores de la violencia, de la obediencia sin discusión y de la teoría racial como elementos que, entre otros, adornaron su argumentario. La comunicación pública estaba al servicio de los intereses del proyecto nacional, de los presupuestos ideológicos del partido único, de la verdad absoluta que se pregonaba de manera sistemática a través de los altavoces del nuevo régimen. Desde el poder, la censura era utilizada como un medio para proteger al pueblo de las ideologías que iban en contra del interés común del que era detentor el partido único o el movimiento que reprentaba la voluntad popular. La libertad de expresión, para estos movimientos autoritarios, no era un derecho: era una falacia de los parlamentarismos que debilitaba la fuerza de voluntad de las nuevas estructuras de poder político, que asumían un supuesto derecho y un deber autoimpuesto de transformar la manera de pensar y de ser de la sociedad. De liberarla de un pensamiento débil y armarla de nuevas ideas para afrontar unitariamente el futuro. Un futuro que, en el caso de Portugal, António de Oliveira Salazar quiso construir con un proyecto que bautizó como el Estado Novo. ${ }^{17}$ Un régimen que se inspiraba en el corporativismo italiano de Mussolini al que se adhirieron, entre

17 Entre otras muchas referencias, véase: ROSAS, Fernando. O Estado Novo nos anos trinta. Elementos para o estudo da natureza económica, social do salazarismo (1928-1938). Lisboa: Estampa, 1996. 
otros, muchos intelectuales de prestigio que validaron y legitimaron en nuevo statu quo nacional. ${ }^{18}$

Salazar utilizó, de hecho, su condición de académico para desarrollar, con una especie de pose profesoral, su gestión política con paternalismo. La propaganda lo retrataba como el gran guía, el gran navegador (en alusión al brillante pasado de la era de los descubrimientos) que sabría sacrificar su vida para llevar a Portugal a buen puerto. ${ }^{19}$ Los portugueses sólo tenían que confiar. Nada más. Salazar era un líder natural. ${ }^{20}$ Sus credenciales como catedrático de la Universidad de Coimbra, cristiano educado en la fe católica y su perfil de trabajador incansable, de valores tradicionales y firmes convicciones patrióticas creado por la propaganda lo convirtieron en el "Chefe". ${ }^{21}$ El futuro de Portugal estaba en sus manos. Así lo creyeron, entre otros, el que sería uno de sus más leales colaboradores, Pedro Teotónio Pereira, que fue subsecretario de Estado (1933-1936) y ministro de Comercio e Industria (1936-1937). Estuvo al servicio de Salazar también como diplomático. Fue embajador de Portugal durante una etapa en la que el dictador era también ministro de Asuntos Exteriores, en países en los que su gobierno tenía intereses estratégicos en el período 1936-1945 y la inmediata posguerra: España (primero como "agente especial", en 1937, luego embajador entre 1938 y 1945), ${ }^{22}$ y Brasil (1945-

18 ADINOLFI, Goffredo. Ai confini del fascismo. Propaganda e consenso del Portugalo salazarista, 1932-1944. Milano: Franco Angeli, 2007.

19 Léase: PENA-RODRÍGUEZ, Alberto. "Los grandes héroes ibéricos. Salazar, Franco y la guerra civil española: prensa y propaganda”. In Journal of Spanish Cultural Studies. http://dx.doi.org/10.1080/14636204.2013.841048

20 Sobre la vida política de António de Olivieira Salazar, léase a DE MENESES, Filipe Ribeiro. Salazar. Uma biografia política. Lisboa, Dom Quixote, $4^{a}$ edição, 2012.

21 MATOS, Helena, Salazar. A Propaganda, 1934-1938, Lisboa, Círculo de Leitores-Temas \& Debates, 2010.

22 Sobre su etapa en España, véase: BRAGA DA CRUZ, Manuel. "Pedro Teotónio Pereira, Embaixador Português em Espanha durante as guerras". In Estudos de Homenagem a Luís António de Oliveira Ramos. Oporto: Faculdade de Letras, 2004, pp. $429-440$. 
-1947). Fue precisamente P. T. Pereira, a la sazón colaborador de la revista conservadora Ordem Nova, el que recibió el encargo de Salazar de diseñar las estructuras del corporativismo portugués. Un diseño político que explicó teóricamente en un libro titulado sintomáticamente $A$ batalha do futuro. Organização corporativa, publicado en Lisboa en 1937.23 Y fue la conciencia de que Estados Unidos era el que impondría las reglas del nuevo futuro lo que hizo que Salazar le confiase a P. T. Pereira la embajada en Washington entre 1947 y 1950. Un período en el cual las dictaduras ibéricas necesitaban posicionarse estratégicamente en el nuevo panorama internacional para lograr mantenerse en el poder. ${ }^{24}$

Tras el acuerdo que dio origen al Bloque Ibérico en 1942 para garantizar la supervivencia de los gobiernos autoritarios peninsualres en medio de la guerra mundial, Portugal y España deseaban ser vistos como dos regímenes que, aunque fascistas, no suponían una amenaza para Europa. Pero sólo Estados Unidos podía convalidar su posición como actores políticos en el nuevo orden internacional. Por eso las relaciones diplomáticas con la nueva potencia global fueron confiadas en la posguerra a P. T. Pereira. Tras un período de aislamiento internacional, los regímenes peninsulares lograrían ser admitidos como miembros de la ONU el 14 de diciembre de 1955, tras un largo proceso de admisión. Justo cuatro años más tarde, a mediados de diciembre de 1959, el presidente de Estados Unidos D. Eisenhower, haría una visita de Estado a ambos países para sellar su integración como naciones adheridas al polo capitalista, dentro de la lógica de la guerra fría. La estrategia diplomática de Salazar,

23 PEREIRA, Pedro Teotónio. A batalha do futuro. Organização corporativa. Lisboa: Livraria Clásica, 1937. Hubo una edición española: La batalla del futuro. Organización corpora tiva portuguesa. Barcelona: Bosch, 1942.

24 Véase: JIMÉNEZ REDONDO, Juan Carlos. Franco e Salazar. As relações luso-espanholas durante a guerra fria. Lisboa: Assirio \& Alvim, 1996. 
basada en el "arte de saber durar", según la acertada expresión de Fernando Rosas, le había funcionado. ${ }^{25}$

La comunidad inmigrante portuguesa en Estados Unidos durante la instauración del Estado Novo era políticamente muy heterogénea. En ella coexistían dos corrientes principales, en torno a un bloque conservador y otro progresista. Tanto el uno como el otro tenían una cierta permeabilidad ideológica. Lo único que los unía era su plena identificación con los valores, símbolos y elementos de carácter nacional. En este universo simbólico, en el que las emociones relacionadas con la representación de la identidad portuguesa y la fuerte propaganda nacionalista del salazarismo se confundían, la comunidad tenía sentimientos encontrados que un sector resolvía manteniendo una actitud ambivalente y ambigüa respecto a la dictadura. El polo conservador, más próximo del salazarismo, agrupaba a un conjunto de visiones ideológicas en el que convivían posiciones opuestas al parlamentarismo democrático europeo, anti-republicanos, anti-comunistas, católicos militantes y monárquicos. El polo liberal, en cambio, aglutinaba a un amplio abanico de ideologías, más o menos progresistas, con una fuerte tendencia de izquierdas en el núcleo de New Bedford, donde existía, desde 1911, el Clube Republicano Portuguez, que era una entidad de tendencia progresista creada para instruir a los inmigrantes lusos. ${ }^{26}$ En esta órbita se situaban los republicanos, los izquierdistas (comunistas, socialistas y anarquistas), anticlericales, etc. que durante la dictadura coincidieron en su frontal oposición a la dictadura. A grandes rasgos, sin embargo, ambos bloques

25 ROSAS, Fernando. Salazar e o Poder. A Arte de Saber Durar. Lisboa: Edições Tinta da China, 2012.

${ }^{26}$ En los anuncios publicitarios en Centro Republicano Portuguez se promocionaba como un "centro de instrução e recreio", con sede en 949 Acushnet Avenue (New Bedford). El lema de la institución decía que era "o lar onde os portuguezes encontram agasalho carinho e simpatia". Véase: Diario de Noticias, 25 de enero de 1936, p. 7. 
convergían en la representación de su discurso político similar en las conmemoraciones patrióticas, que el Estado Novo siempre intentaba instrumentalizar para ganar adeptos. ${ }^{27}$ Ambas corrientes poseían instituciones gremiales desde las que promocionaban sus idearios políticos, en algunos casos con publicaciones periódicas propias, como Liberdade, órgano de la Aliança Liberal Portuguesa de New Bedford (Massachusetts), donde se encontraba el epicentro de la colonia de Nueva Inglaterra.

La cercanía atlántica, una mayor interacción política derivada de un agrupamiento urbano, con publicaciones periódicas influyentes como el Diario de Noticias, la mayor presencia del cuerpo diplomático portugués (con la embajada de Washington y los consulados generales de Boston y New York), propiciarion una mayor implicación de los miembros de la colonia en los Estados de la costa Este en la vida política de Portugal. California no vivió ajena a las campañas de propaganda del Estado Novo y sus opositores, pero su situación de lejanía y la falta de exiliados políticos relevantes, como ocurrió en los Estados de Massachusetts y New York, la mantuvo siempre en un segundo plano. Entre todas las ciudades en las que se registró algún tipo de actividad propagandística de cualquierra de los actores políticos implicados durante el Estado Novo, fue New Bedford la que cobró mayor protagonismo, particularmente durante el exilio de João Camoesas, que se extendió hasta 1951, como se verá a continuación.

27 Según la apreciación de Rui Antunes Correia “(...) sempre que está em causa a afirmação de Portugal como principio de identidade cultural e nacional de imigrante luso-americano impõe-se a todos os sectores um verdadeiro pacto social, que silencia toda a sorte de oposições, entendidas nesses momentos, como infidelidades patrióticas. (...)". Op. cit., p. 92. 


\section{La colonia y su campaña contra la dictadura}

La colonia portuguesa en Estados Unidos no fue ajena al proceso de cambio de régimen que se desarrolló en Portugal con la fundación del Estado Novo salazarista. No sólo porque los periódicos luso-americanos informaban a los interesados inmigrantes portugueses de todo lo que ocurría en su país, sino porque esto afectó muy especialmente a su compresión de la realidad portuguesa, a su grado de compromiso político con su país de origen y a su papel como nacionales u oriundos de un Estado que estaba en las antípodas ideológicas del sistema político norteamericano. Afectó, sobre todo, porque algunos periódicos editados por miembros de la colonia se convirtieron en foros de apasionados debates y polémicas sobre el significado político del Estado Novo, sobre la figura de Salazar, sobre el contraste manifiesto con los valores de la sociedad que los acogía, o sobre la falta de libertades en el Portugal salazarista.

Las publicaciones periódicas que los inmigrantes editaban adquirieron, además, un nuevo valor propagandístico, con campañas a favor y en contra del salazarismo organizadas por diversas instituciones y personajes que trabajaban para el régimen o que ejercían un papel como opositores. La libertad de prensa y el decidido afán por alimentar, a veces, polémicas que podrían incrementar la tirada, permitía que en el mismo periódico pudieran publicarse artículos que defendían ideas antagónicas. También hubo publicaciones creadas para el adoctrinamiento político y otras cuyas líneas editoriales adoptaron, en determinados momentos o contextos, un posicionamiento político más o menos próximo al Estado Novo o sus opositores. En general, los periódicos tuvieron una especial relevancia como instrumentos de propaganda durante el proceso de consolidación del Estado Novo, particularmente entre 1935 y 1940. Para conseguir persuadir a un público amplio, los preferidos por salazaristas y anti-salazaristas eran los que tenían una mayor 
difusión. Entre ellos, en los años treinta y cuarenta destacaban en Nueva Inglaterra el Diario de Noticias y los semanarios O Colonial, O Independente, O Popular y Novidades. ${ }^{28}$ En New York City, el más influyente era A Luta, del padre José Cacella. Pero, entre 1937 y 1938, circularon dos semanarios de propaganda anti-fascista, fundados y dirigidos por José Alves Rodrigues, ${ }^{29}$ que trataron de agitar la colonia en New York y New Jersey contra el gobierno de Portugal entre 1936 y 1938, y que llegaron a inquietar al gobierno portugués. Eran $O$ Bacamarte ("órgão de combate pela verdade e pela justiça”) y $A$ Plebe. ${ }^{30}$ En estos años, existió incluso una alianza

28 Desgraciadamente, los contenidos de algunos de ellos sobre este aspecto no han podido ser estudiados por la inexistencia de colecciones en los archivos americanos o portugueses.

29 José Alves Rodrigues inició su campaña contra el Estado Novo publicando varios artículos en $O$ Colonial (Farihaven, Mass.). Léase, entre otros: "A corda do enforcado ou o Judas da Ditadura". O Colonial, 7 de junio de 1935. (Arquivo Histórico Diplomático, embajada de Portugal en Washington, caja $\left.\mathrm{n}^{\circ} 37\right)$.

30 o Bacamarte fue fundado el 1 de septiembre de 1936 en Newark y dejó de publicarse en 1937. Era un tabloide ilustrado, de 8 páginas. En un artículo titulado "Liberdade", firmado por Trinidade Coelho el 22 de diciembre de 1936 se hace una defensa de ella en los siguientes términos: "Liberdade! Mágica palavra que fascina todos os homens, desde o mais selvagem ao mais civilizado! Ideal a que de boa vontade todos sacrificariam os seus haveres, ainda os mais preciosos! Alta e luminosa imagem que a criança ao nascer traz já gravada no coração, e que o ancião, prestes a adormeces no derradeiro sono, ainda afaga a caricia! ¿Donde provem o teu sagrado prestígio? É que, para ser humano, a liberdade é condição indispensável de felicidade. ¿De qué serviria a vida se não pudéssemos gozá-la livremente? ¿De que serviria termos orgãos para agir, espirito para pensar, coração para sentir, se todas essas faculdades houvessem de ser violentamente abafadas por uma força externa? Jamais será o ideal da Humanidade, em cujo coração a necessidade de Liberdade é innata - jamais será o ideal da Humanidade a sorte de um prisioneiro algemado! Liberdade! Eis a força, o movemento, a vida, eis o caminho para esse fim supremo a que devemos aspirar incesantemente: a justiça entre todos e para todos (...)".(O Bacamarte, $n{ }^{\circ}{ }^{5}$, año 1, 22 de diciembre de 1936, p. 1). A Plebe, de formato y contenidos similares a $O$ Bacamarte, se editó entre 1936 y 1938, con sede en New York City. Ambos sufrieron las presiones del régimen para impedir su publicación, según se desprende de la documentación diplomática portuguesa. Véase: Arquivo Histórico Diplomático, Embajada de Portugal en Washington, caja $\mathrm{n}^{\circ} 36$. Carta confidencial enviada por Mons. Joseph Cacella al embajador de Portugal, João António de Bianchi, 5 de agosto de 1938; AOS/SGPCM-GPM, caja n. ${ }^{\circ}$ 5, PC-156, 3, n. ${ }^{\circ} 4$. Oficio n. ${ }^{\circ} 1273$ del subdirector del Secretariado de Propaganda Nacional, António Eça de Queiroz, al Presidente do Conselho de Ministros, 19 de septiembre de 1938. 
de los inmigrantes ibéricos en Manhattan contra las dictaduras de Franco y Salazar, plasmada a través de la colaboración en un semanario titulado $\mathrm{La} \mathrm{Voz}$, que disponía de una sección-edición en portugués dirigida por Gil Stone. ${ }^{31}$ A Tribuna era también un periódico muy leído entre la comunidad de Newark (N. Jersey), aunque sólo de publicó entre 1931 y 1934. Allí, el nuevo Luso-Americano de Vasco S. Jardim cobraría todo el protagonismo e influencia a partir de su reaparición en 1939, pero ya entonces el debate en torno al Estado Novo había perdido interés entre los inmigrantes.

En California, los semanarios A União Portuguesa (hasta 1942) y el Jornal Português, de Oakland, fueron los periódicos con mayor influencia política en la colonia. ${ }^{32}$ En el caso de los periódicos californianos, su discurso editorial, en general, era tolerante y próximo al salazarismo, pero se publicaron también artículos críticos con la dictadura, a pesar de la presiones del consulado en San Francisco. 33

Como relata en su estudio Rui Antunes Correia, ${ }^{34}$ durante los años treinta era frecuente la convocatoria de actos públicos, por uno u otro bando, en defensa de sus respectivas causas para ganar apoyos en la colonia. Entre los opositores, la figura más destacadafue

31 Diferentes números del semanario $L a$ Voz se encuentran en el Archivo Diplomático de Lisboa. Véase la documentación histórica de la Embajada de Portugal en Washington, caja $\mathrm{n}^{\circ} 13$.

32 A União Portuguesa adoptó un discurso editorial abiertamente contrario a la dictadura en el período en el que José Trinidade Salgueiro fue su editor, entre 1940 y 1942. El 8 de junio de 1942 el periódico se declara anti-salazarista a través de la transcripción de un texto de Lúcio dos Santos, profesor de la Universidad de Oporto exiliado en Brasil. Véase: A União Portuguesa, n $^{\circ} 2803,8$ de junio de 1942, p. 1.

33 Arquivo Histórico Diplomático, Embajada de Portugal en Washington. Oficio del Cónsul de S. Francisco, G. Armas do Amaral, al encargado de Negocios de la embajada, João de Deus Ramos, 4 de agosto de 1937. En el oficio el cónsul explica que consiguió que el director e A União Portuguesa prohibiese los "artículos subversivos" de José Trindade Salgueiro en el periódico.

34 Correia, Rui Antunes. Op. cit. 
João Camoesas, que había sido ministro de Instrução Pública en la República en dos ocasiones. ${ }^{35}$ La acción opositora se concentró,

35 João José da Conceição Camoesas nació el 13 de marzo de 1887 en la ciudad fronteriza de Elvas. Allí fue fundador, propietario y director del periódico A Fronteira. En 1911, se integró en la logia masónica de Elvas bajo el nombre de Câmara Pestana. En 1919, se licenció en la Facultad de Medicina de Lisboa con la máxima calificación, otorgada por un tribunal presidido por el profesor monárquico Azevedo Neves. Miembro destacado del Partido Republicano Portugués, fue diputado entre 1916 y 1926, vocal del consejo de administración de la Caixa Geral dos Depósitos, Chefe de Repartição de Higiene da Câmara Municipal de Lisboa y médico escolar. Fue elegido diputado por Elvas en 1916 y por Portalegre en 1919, 1921, 1922 y 1925. Fue ministro de Instrução Pública en dos períodos durante la etapa de la primera República (1910-1926). Primero, en el gobierno de António Maria Silva, entre el 9 de enero de 1923 y el 15 de noviembre del mismo año. Durante este mandato, presentó un ambicioso proyecto de inversión en la educación pública, la "Proposta de Lei sobre a Reorganização da Educação Nacional" (conocida popularmente como "reforma Camoesas"), que propugnaba en la organización científica del trabajo basada en la teoría de Frederick Taylor (1856-1915) y en otras experiencias pedagógicas internacionales, sobre todo norteamericanas, pero que no sería aprobado. Uno de los episodios más recordados de su etapa como diputado y miembro del gobierno portugués fue su discurso de réplica pronunciado el 16 de julio de 1925 en el Parlamento, que duró más de nueve horas. Entre el 1 de agosto y el 17 de diciembre de 1925 vuelve a ocupar el mismo puesto bajo el gobierno de Domingos Pereira. En 1919, fue designado médico escolar adjunto y realizó en comisión de servicio un viaje a Estados Unidos en el mes de octubre para analizar los servicios médico-escolares. En 1921, colaboró con la Universidade Popular Portuguesa y, en 1925, se encargó de la sección de Fisiología del Instituto de Orientação Profissional. Colaboró en diversas publicaciones periódicas en Portugal, como Seara Nova, Portugal, Boletim da Inspecção Geral da Sanidade Escolar, en los que se destacó por sus artículos relacionados con la medicina escolar y la organización del trabajo. Publicó el libro O Trabalbo Humano, que es la primera obra portuguesa basada en la teoría de F. Taylor, que defendía el desarrollo humano a partir de la la fisiología del esfuerzo. Fue condecorado con la Gran Cruz de Alfonso XIII de España en el transcurso del Congreso Luso-Español para el Progreso de las Ciencias. Entre sus publicaciones se encuentrasn las siguientes referencias: A Medicina Escolar na América do Norte, O Taylorismo e a organización científica do trabalho, Do Ámbito da Educação Física, A Régia dos Tabacos e o Futuro de Portugal y Teoria da Renovação Portuguesa. Con la instauración de la dictadura, fue deportado a Angola y, en 1929, autorizado a exiliarse en Estados Unidos. Según las pesquisas de Rui A. Correia, Camoesas podría pertenecer a la Ordem Maçónica Rosa Cruz de New Bedford (op.cit., p. 143), que se declaró abiertamente opositora del Estado Novo (op. cit., p. 141). La viuda de João Camoesas era Aurora Alves Camoesas. Tenían dos hijos: Alfonso y João Augusto. Alfonso que fue sargento del ejército americano, condecorado varias veces por sus actos de guerra en la guerra de Corea. João Augusto Camoesas residió en Portugal. Cuando fallece el 11 de noviembre de 1951, la familia dona su cuerpo a la Tufts Medical School. Después sería incinerado y enviado a Portugal, donde recibió sepultura en el cementerio de Elvas. Su casa familiar se encontraba en Vila Nova de Estefanía, ${ }^{\circ} 6$ (Elvas). Todos los datos aquí reunidos sobre João Camoesas fueron recogidos de las siguientes fuentes: Enciclopédia Luso-Brasileira 
fundamentalmente, en Nueva Inglaterra. No existe constancia de un movimiento de oposición política en California. Camoesas fue el líder que organizó y orquestó la oposición política a la dictadura en Estados Unidos a partir de su llegada, el 12 de junio de 1929, al puerto de Providence, en Rhode Island. ${ }^{36}$ Abílio de O. Águas, que fue destituido de su puesto consular por el gobierno de la dictadura en noviembre de 1929, adoptó un papel más discreto públicamente; no utilizó la prensa como instrumento de propaganda. Fue, sin embargo, un leal colaborador de João Camoesas hasta su fallecimiento en Taunton (Mass.) el 11 de noviembre de 1951.

Poco después de instalarse en Massachusetts, Camoesas creó una red de colaboradores y estableció una relación permanente con la prensa luso-americana de la costa Este. Su prestigio como ex ministro y su condición de médico y académico, le brindaron un inmediato reconocimiento por parte la comunidad inmigrante portuguesa, que se sentía honrada de poder acogerlo como miembro de la colonia. Entre otros aspectos interesantes, Rui A. Correia se refiere a un hecho de gran relevancia simbólica que tuvo una repercusión periodística en la prensa de Nueva Inglaterra: el homenaje organizado en su honor por el Clube Republicano Portuguez de New Bedford con

(tomo letra C, p. 627); Governo de Portugal. Galeria de ministros de Educação (www. portugal.gov.pt); Correia, Rui Antunes, op. cit., p. 109; Infopédia: http://www.infopedia. pt/joao-camoesas>; Diario de Noticias de New Bedford (diversos números). Sobre su actividad como ministro de educación pueden leerse también los siguientes autores: Casulo, José Carlos Oliviera. "A educação superior no projecto Camoesas". In Actas do Primeiro Congreso Internacional Galego-Português de Psicopedagogia. Braga: Universidade do Minho, 2009. Véase en línea: http://repositorium.sdum.uminho.pt/ bitstream/1822/9931/1/c\%C3\%B3pia\%20do\%20texto\%20publicado\%20nas\%20actas.pdf. También: Bandeira, Filomena. "Camoesas, João José da Conceição". In: Nóvoa, António (dir.). Dicionário de educadores portugueses. Porto: Asa, pp. 237-241. Nóvoa, António. "O projecto da Reforma Camoesas (1923): uma referência histórica no pensamento do Prof. João Evangelista Loureiro". Revista da Universidade de Aveiro -série Ciências da Educação, vol. 7, n. ${ }^{\circ} 1-2,1986$, pp. 113-121.

36 Diario de Noticias, 13 de junio de 1929, p. 1. La información cuenta que João Camoesas se instaló provisionalmente en New Bedford, en la casa de José Pacheco Correia. 
ocasión de su $44^{\circ}$ cumpleaños, el 13 de marzo de 1931.37 Durante el acto fue descubierto un retrato del político portugués que, en diciembre de 1933, sería robado cuando la asamblea del Clube Republicano se negó a colocar una fotografía del general Carmona en la misma sala, a propuesta por un grupo de socios. 38

El protagonismo público que adquirió desde el mismo día que llegó a Estados Unidos, fue aprovechado por el político elvense para hacer campaña a favor de la democracia en Portugal. No era la primera vez que João Camoesas estaba en Nueva Inglaterra. El 31 de diciembre de 1919, aprovechando su participación en la Conferencia Internacional de Trabajo en Washington como representante de Portugal, había pronunciado una multitudinaria conferencia en el New Bedford Theatre, promovida por el Gremio Cosmos. Según cuenta una crónica de A Alvorada fue la mejor de todas las que hasta entonces allí se habían realizado. ${ }^{39}$ Camoesas habló con orgullo sobre la historia de Portugal. Se remontó a Viriato para explicar el proceso de evolución histórica del país hasta el advenimiento de la República, que defendió frente a sus críticos. Reconoció que no era católico, pero sí respetuoso con esta y otras creencias religiosas. El discurso de Camoesas “(...) numa linguagem chã, compreensível e eloquente, foi contantemente interrompido por

37 Correia, Rui Antunes. Op. cit., pp. 109-110.

38 El episodio generó un gran malestar en la colonia. Los periódicos informaron sobre el asunto con detalle porque, además, fue denunciado ante la policía. Rui A. Correia recoge una crónica del Diario de Noticias cuyo trecho se reproduce: "Este retrato do distinto médico e imigrado político fôra inaugurado pelos republicanos portugueses pouco depois da sua chegada a este paiz, em sessão pública, por ocasião de uma data comemorativa, realisada por aquela agremiação. Atribue-se o furto do retrato ao grupo de socios, despeitados com a a titude da assembleia daquele gremio, a qual, por tres ou quatro vezes, e por forte maioria, se tem oposto ao descerramento, na mesma sala, do retrato do sr. General Carmona, actual Chefe de Estado Portugues. A Assembleia, tomando como desconsideração para si o acto practicado, não só apresentou queixa, como ordenou que pelos fundos da colectividade fosse dádo um prémio de $\$ 100$ a quem descobrisse o autor da proeza". Diario de Noticias, n. ${ }^{\circ} 4445$, 18 de diciembre de 1933. Citado por Rui A. Correia. Op. cit., pp. 110-111.

39 A Alvorada, ano IX, n 536, 1 de enero de 1920, p. 1. 
bravos, apoiados, muito bem, acompanhados de estrondosas salvas de palmas. Foi um delírio! (...)". ${ }^{40}$ Aquella aplaudida visita a New Bedford a finales de 1919 habría influído, probablemente, en su decisión de fijar su exilio en Nueva Inglaterra, donde había tenido ocasión de comprobar la pujanza de la comunidad inmigrante portuguesa, que entonces atravesaba por uno de sus mejores momentos económicos. Antes de iniciar su exilio en Estados Unidos, João Camoesas estuvo exiliado en Angola, a donde había llegado tras haber sido detenido en Lisboa el 17 de febrero de 1928 y encarcelado hasta su deportación a África, el 4 de mayo del mismo año. ${ }^{41}$ Desde allí, el 28 de octubre de 1928 envía una carta abierta a António de Oliveira Salazar en la que lo acusa de colaborar cínicamente de la dictadura:

“(...) Professor de direito numa sociedade democrática, o sr. é o único sustentáculo dum governo que nega o direito numa sociedade democrática. Mestre de sciencias económicas realiza uma obra que ergue 'a razão do Estado' acima das possibilidades nacionais. Católico praticante, em vez de amar o próximo a si próprio, associa-se a uma política de ódio, imposta pela violência e mantida pela crueldade. Moralista consente na sustentação da Policia de Informações, cuja administração é um descalabro e cuja acção é uma ignonímia. Intelectual e homem de sciencia sugeita-se á chefia de Vicente de Freitas que é a personificação da ignorancia e da boçalidade. Emfim, dizendo-se patriota colabora

\footnotetext{
40 Ibídem.

41 En Angola se estableció en Santomé, donde no encontró oportunidades laborales. Después de varios intentos para buscar recursos de subsistencia en la colonia portuguesa y el Congo Belga, decidió pedir asilo en la Embajada de Estados Unidos el 8 de marzo de 1929. Sus peripecias antes de llegar a territorio de Estados Unidos en mayo de 1929 pueden leerse en un artículo firmado por él mismo en el Diario de Noticias el 14 de marzo de 1938 ( $\mathrm{n}^{\circ}$ 5727, pp. 1 y 5), titulado "Anotação á margem. Documento elucidativo". Este documento es citado por Rui A. Correia en su trabajo.
} 
na manutenção de um sistema governativo que em Genebra enchovalhou a dignidade da Pátria e que, sendo um motivo de fundas divergênicias internas, lhe compromete o futuro e inferiorisa o presente. (...) Os seus amigos não se cansam de apregoar a sua discordância com certos actos do governo e o seu desprezo pela quase totalidade dos seus colegas de gabinete, incluindo o respectivo presidente: contudo, continua a acamaradar com eles. Se há cortes, apressam-se a espalhar que o exército será o primeiro nos sacrifícios: mas o orçamento da guerra ficou quase na mesma. Se há acumulações, esboça propósitos audaciosos e intransigências irredutíveis: no entanto, vai abrindo alçapões na lei. Se há deportações iminentes, lança-se na circulação o boato de que se opõe à sua efectivação: mas, para trazerem cerca de duzentas pessoas, vêm dois barcos propositadamente a África, gastando milhares de contos. E seria infindável a lista dos postiços com que o senhor encobre ou consente que lhe encubram a sua verdadeira personalidade, aquela que a sua acção revela e os factos definem." 42

Cuando en 1929 llega finalmente a Estados Unidos, Camoesas se establece con un consultorio médico en la pequeña ciudad de Taunton (Massachusetts), muy cerca de New Bedford, y desde el primer momento participa en decenas de actos organizados por las instituciones de la colonia. Lo que le permitiría conocer su situación social, política y económica en poco tiempo, relacionarse con sus líderes más destacados y convertirse en una figura de referencia. ${ }^{43}$

42 AOS/CO/PC-3A, P 1. Carta de João Camoesas a Oliveira Salazar, 28 de octubre de 1928. Un trecho de esta carta es utilizada por el propio João Camoesas en uno de sus artículos contra la dictadura publicados en el Diario de Noticias en 1937. Véase: Correia, Rui Antunes. Op. cit., pp. 143-144.

43 El 9 de abril de 1933 pronunció una conferencia en el Club Republicano Português de Pawtukect para conmemorar el 9 de abril, fecha en la que varios miles de 
Sus apariciones en noticias de la prensa luso-americana, le otorgaron un prestigio aún mayor y le dieron la autoridad necesaria para servirse de los periódicos de la colonia en contra de la dictadura. Su vitola de ex ministro republicano de Instrução Pública y su implicación directa en las actividades públicas de la comunidad luso-americana le conferirían, además, la legitimidad necesaria y el derecho para intentar persuadir a sus conciudadanos. Sus dotes oratorias, su capacidad discursiva y su experiencia periodística como fundador y director del periódico A Fronteira en su Elvas natal, le propiciaron una posición de liderazgo dentro de la colonia.

A partir de 1935, cuando el Estado Novo comenzaba a consolidar sus estructuras y la propaganda salazarista se hacía sentir en Estados Unidos, decidió impulsar una campaña a favor de la democracia en Portugal. La prensa luso-americana fue su principal medio para tratar de hacer oposición al régimen fascista luso. Difundió la mayor parte de sus artículos contra la dictadura a través del Diario de Noticias de New Bedford y O Colonial de Fairhaven. Pero también publicó algunos textos, con un tono más pedagógico que político, en $O$ Heraldo Portuguez. ${ }^{44}$ João Camoesas inició su campaña de prensa contra Salazar en el semanario O Colonial. Allí, publicó una serie de textos en los que relata los ataques del Estado Novo contra los derechos de los trabajadores portugueses, ${ }^{45}$ y sobre su política

soldados portugueses murieron en combate durante la batalla de la Lys, en la Primera Guerra mundial. Véase: Diario de Noticias, $\mathrm{n}^{\circ} 1903,7$ de abril de 1933, p. 1.

${ }^{4}$ En total, se ha catalogado más de un centenar de artículos, la mayoría de los cuales fueron publicados en el Diario de Noticias de New Bedford. Como simple muestra de sus artículos en los otros periódicos, léanse en O Heraldo Portuguez: "O ideal pacifista", no 29 (año 16), Natal de 1936, pp. 1 y 2; "Apologia da liberdade", n. ${ }^{\circ} 25,25$ de dociembre de 1934 , pp. 1 y 2 . Y en O Colonial: "O Monstro Revela-se": n. ${ }^{\circ} 408,10$ de agosto de 1936, p. 1 .

45 João Camoesas: "O Monstro revela-se". O Colonial, 10 de mayo de 1935, p. 1 (Arquvio Histórico Diplomático, Embajada de Portugal en Washington, caja n. ${ }^{\circ} 37$ ). 
colonial. ${ }^{46}$ Uno de los momentos más combativos en la guerra de propaganda entre Camoesas y los agentes del Estado Novo, ocurrió cuando el nuevo cónsul de Providence, Manuel Caetano Pereira, rebatió de forma sistemática sus argumentos contra la dictadura a través de la publicación casi diaria de artículos en el Diario de Noticias, en el contexto de una encendida polémica que duró casi un año, entre 1937 y $1938 .{ }^{47}$ Desde que inició su cruzada contra Salazar, João Camoesas no cejó de combatir el salazarismo publicando decenas de artículos, memorandos y manifiestos en contra del Estado Novo hasta sus últimos días. En el artículo publicado el 3 de septiembre de 1937 en el Diario de Noticias bajo el título "Parábola do homem e a bêsta", resume en forma de "memento" los motivos por los que se proclama anti-salazarista, cuyos argumentos expondrá en sus sucesivos textos publicados a lo largo de su prolongada campaña contra el Estado Novo:

"Provou-se que as mesmas pessôas que acusam republicanos mortos e vivos de haver promovido confiscações, monopolisado o poder, perseguido crenças, oprimido minorias, levado o pais á guerra por méro partidarismo, aplaudem e apoiam Oliveira Salazar, o qual sem dúvida e incontestavelmente:

Confiscou os bens da Maçonaria Portuguêsa;

Declarou ilegal a existência de todos os partidos;

Converteu os empregos públicos em benfícos revervados exclusivamente para os seus apaniguados;

Perseguiu e persegue violentamente todas as oposições;

Tornou obligatória a afiliação da juventude portuguêsa num organismo político que o apoia; Organisou e mantem o mais

\footnotetext{
46 João Camoesas: "O Monstro Revela-se". O Colonial, 10 de agosto de 1936 (Arquivo Histórico Diplomático, Embajada de Portugal en Washington, caja n. ${ }^{\circ} 37$ ).

47 El relato de Rui Antunes Correia es muy exhaustivo en este aspecto. Véase su tesis de mestrado. Op. cit., pp. 104-168.
} 
completo e absoluto monopólio do poder jamais existente em Portugal;

Levou á Nação cladestinamente á guerra com a Espanha por motivos exclusivos da sua política pessoal”. ${ }^{48}$

El exilio de João Camoesas en Estados Unidos y sus campañas de prensa en contra de Salazar, especialmente intensas en el período de la Guerra Civil de España (1936-1939), removió muchas conciencias en la comunidad de inmigrantes lusos e hizo que no pocos de ellos se movilizazen a favor de la democracia en Portugal. Muchos creyeron que, después de la victoria de Estados Unidos en la Segunda Guerra mundial, en la que combatieron hasta 35.000 luso-americanos, según los opositores al régimen, el salazarismo había llegado a su fin. Al finalizar el conflicto, en su calidad de presidente del Portuguese-American Commitee Pro Democracy, João Camoeas hizo público en la prensa luso-americana un telegrama enviado a Salazar en el que le pide que entregue "cristianamente" el poder a los demócratas portugueses:

"Os exércitos vitoriosos da Demoracia mundial liquidaram finalmente os poderes opressores da Europa. Todas as oligarquias que deturparam as institucições democráticas do velho continente obstruindo sua evolução foram abrangidas pela derrota hoje anunciada oficialmente. Resta-vos por isso uma única maneira de bem servir Potugal: entregar imediatamente o governo do pais a verdadeiros democratas. Cristamente, sem ódio nem espírito de represalia, satisfaço minha consciencia apontando

48 "Anotação á margem: Parábola do homem e a bêsta". Diario de Noticias, n. ${ }^{\circ}$ 5570, 3 de septiembre de 1937, p. 1. 
caminho reintegrar Portugal normalidade política sem sangue nem violência". 49

El salazarismo militante aplicó toda su influencia para impedir que la colonia se convirtiese en un núcleo de oposición que, eventualmente, podría ejercer alguna presión sobre el gobierno estadounidense $\mathrm{u}$ otras instituciones americanas contra el gobierno luso. Además, era imporante para el gobierno portugués evitar que el anti-salazarismo pudiese extenderse por la emigración portuguesa y perturbar la situación nacional. De acuerdo con la expresión de António Ferro, "iluminar" a los emigrantes portugueses se convirtió en un asunto de Estado.

49 New Bedford Whaling Museum Research Library. Portuguese Immigration Records, caja $\mathrm{n}^{\circ}$ 2. Recorte de imprensa: "Um telegrama de João Camoesas ao Chefe do Governo Oliveira Salazar". Artículo publicado en el Diario de Noticias, n. ${ }^{\circ} 7907$, 9 de mayo de 1945, p. 1. 